\title{
AÇÕES DE EXTENSÃO VOLTADAS ÀS TECNOLOGIAS AGRONÔMICAS, ZOOTÉCNICAS E AMBIENTAIS COM AGRICULTORES FAMILIARES EM DOURADOS -MS: FRUTICULTURA, HORTICULTURA E SISTEMAS AGROFLORESTAIS ${ }^{1}$
}

\author{
Euclides Reuter Oliveira ${ }^{2}$ \\ Marisa Bento Martins Ramos ${ }^{3}$ \\ José Luis Fornasieri \\ Omar Daniel ${ }^{5}$ \\ Marisa de Fátima Lomba de Farias ${ }^{6}$
}

\begin{abstract}
Resumo
A agricultura familiar apresenta requisitos relevantes: fortalece o trabalho familiar; viabiliza a produção de alimentos para a subsistência das famílias; e fornece à sociedade, alimentos de qualidade e economicamente acessíveis. Considerando essa relevância em assentamentos e comunidades quilombolas, a partir de 2008 foram desenvolvidos trabalhos de extensão nos assentamentos Amparo e Lagoa Grande e na Comunidade Quilombola em Dourados-MS. As atividades se pautaram na participação dos grupos e da equipe executora, que gradativamente definiram temas importantes diante da realidade de cada comunidade. Após definição dos locais e das atividades, coletivamente, iniciou-se a atividade de fruticultura e horticultura no assentamento Amparo e comunidade Quilombola e a implantação de sistemas agroflorestais finalizados com eucalipto e bovinos no assentamento Lagoa Grande. Criaram-se espaços sociais de saberes entre as comunidades e a UFGD, propícios para a apresentação de técnicas apropriadas visando a autossuficiência em produção e na geração de renda. Parte dos produtos foram consumidos pelas famílias e o excedente foi comercializado em diversas pequenas feiras no município e na UFGD.
\end{abstract}

Palavras-chave: Extensão rural, manejo sustentável, sistema agroecológico

\footnotetext{
${ }^{1}$ Financiado pelo CNPq, MEC, e UFGD

${ }^{2}$ Docente do curso de Zootecnia - Universidade Federal da Grande Dourados, Dourados/MS (FCA-UFGD). Doutorado em Zootecnia (UFLA). Coordenador do projeto: "Transferência de tecnologias agronômicas, zootécnicas e ambientais a agricultores familiares em Mato Grosso do Sul - CNPq - UFGD”. E-mail: euclidesoliveira@ufgd.edu.br 3 Engenheira Agrônoma, Bolsista do CNPq. Mestrado em Agronomia (UFMS). E-mail: mbentomr@hotmail.com ${ }^{4}$ Docente do curso de Agronomia - Universidade Federal da Grande Dourados, Dourados/MS (FCA-UFGD) E-mail: soschi@bol.com.br

${ }^{5}$ Docente do curso de Agronomia - Universidade Federal da Grande Dourados, Dourados/MS (FCA-UFGD). Doutorado em Doutorado em Ciência Florestal (UFV). E-mail: omardaniel@ufgd.edu.br

${ }^{6}$ Docente do curso de História - Universidade Federal da Grande Dourados, Dourados/MS (FCH-UFGD). Doutorado em Sociologia (UNESP). E-mail: marisa.lomba@ufgd.edu.br
} 


\title{
EXTENSION ACTION, WITH FAMILY HUSBANDMAN IN DOURADOS-MS, TOWARDS TO AGRONOMIC TECHNOLOGY, ZOOTECHNICS AND ENVIRONMENT: FRUIT-GROWING, HORTICULTURE AND AGROFORESTRY SYSTEM
}

\begin{abstract}
Family farming has relevant requirements: strengthens family work; enables the production of food for the subsistence of the families, and provides to society, food quality and affordable. Considering this relevance in rural settlements and quilombolas communities, from 2008 were developed extension work in the settlements Amparo and Lagoa Grande and Quilombo Community in Dourados, MS. The activities were based on the participation of groups and the executive team, which gradually defined important issues facing the reality of each community. After defining the locations and activities collectively began the activity in fruit growing and horticultural in Amparo settlement and Quilombo community and the establishment of agroforestry systems finished with eucalyptus and dairy cattle in Lagoa Grande settlement. It created social spaces of knowledge between communities and UFGD, conducive to the presentation of appropriate techniques aimed at self-sufficiency in production and income generation. Part of the products were consumed by households and the remainder was marketed many small fairs in the city and UFGD.
\end{abstract}

Key Words: Rural Extension, Defensible Manegement, Agroecological system

\section{INTRODUÇÃO}

A agricultura familiar, atualmente, tem papel fundamental no equilíbrio da economia local e no incentivo à permanência da população no campo, dentre os quais fornecer alimentos com qualidade nutricional para a subsistência familiar, de baixo custo e de boa qualidade para a sociedade de modo geral, e ainda, a partir da produção resultante do trabalho familiar gerar trabalho e renda para todos os seus membros.

O fortalecimento da agricultura familiar depende não só da intensificação das políticas públicas, mas também do diálogo entre os saberes populares e o conhecimento científico e tecnológico, objetivando maximizar o uso de recursos locais, produzirem alimentos com mais qualidade e com menor risco para o meio ambiente (FONTANETTI; SANTOS, 2010)

Neste sentido, existe a necessidade de integração das diversas Instituições de Ensino, Extensão e Pesquisa em âmbitos Municipal, Estadual e Federal, com o objetivo de aperfeiçoar os recursos humanos disponíveis para que os agricultores familiares tenham acesso às tecnologias viáveis para impulsionar a produção. $\mathrm{E}$ dessa forma, possibilitar esse grupo conhecer novas tecnologias, quer seja voltadas às atividades de pecuária e/ou de agricultura, auxiliando-os na inserção no setor produtivo com competitividade, sem desqualificar as características e especificidades de seu trabalho, importante para a reprodução social das famílias. Portanto, torna-se 
imprescindível, criar alternativas qualitativas de capacitação aos agricultores familiares voltada ao uso de tecnologias viáveis à produção e princípios agroecológicos considerando as características da área e seus saberes, pois muitas alternativas são criadas e recriadas no cotidiano das famílias. Alternativas essas aprendidas na trajetória de vida, presentes em suas memórias e estruturando um saber fazer próprio. De acordo com Buainain et al. (2003), o desenvolvimento da agricultura familiar moderna requer o apoio de um conjunto de serviços técnicos especializados, além de equipamentos apropriados à sua escala e sistemas de produção e consideram ainda necessário no Brasil a implementação de políticas agrícolas e agrárias voltadas para agricultores familiares.

A agricultura familiar, no Brasil, apresenta perfil multifuncional, pois produz alimentos e matérias-primas, gerando mais de $80 \%$ da ocupação no setor rural e favorece o emprego de práticas produtivas ecologicamente mais equilibradas, como a diversificação de cultivos, o menor uso de insumos industriais e principalmente a preservação do patrimônio genético. Além disso, este setor permite uma distribuição populacional mais equilibrada no território, por demandar maior número de trabalhadores em relação à agricultura patronal, normalmente associada à monocultura (VILELA; ARAÚJO, 2006). O potencial de novas formas de mercado para a agricultura familiar ainda está para ser explorado. Provavelmente muitas redes de produção e comercialização alternativas já constituem uma opção consolidada para um amplo leque de agricultores (NIEDERLE, 2009.9).

O fortalecimento da agricultura ecológica ou orgânica principalmente pelo agricultor familiar vem da necessidade de consumo de alimentos saudáveis que a sociedade moderna exige e por conseqüência da preservação da natureza, bem como o aumento do valor da comercialização (BURG; MAYER, 2001).Com a produção ecológica, há um ganho social significativo, ganham o meio ambiente, os consumidores e os produtores (CAPORAL; COSTABEBER, 2007).De acordo com os mesmos autores, saber que uma expressiva parcela dos agricultores familiares está realizando um processo de transição para estilos de agricultura sustentável, diminuindo impactos ao meio ambiente e à saúde e preservando os recursos naturais é, sem dúvida, um fator de esperança para as futuras gerações, assim como indica um aspecto favorável para a melhoria de vida, tanto no âmbito da segurança alimentar quanto na ampliação de renda, das gerações atuais.

Desse modo, considerando a importância do fortalecimento da agricultura familiar para permanência de famílias na terra, para nela residir e produzir desenvolveu-se atividades de extensão nas comunidades citadas abaixo através do desenvolvimento de trabalhos sociais e agrícolas, com apoio da Incubadora de Tecnologias Sociais e Solidárias (ITESS-UFGD), Agência de Desenvolvimento e Extensão Rural - AGRAER e Prefeitura Municipal de Dourados. Avaliou-se ainda, o potencial dessas atividades para o desenvolvimento social e sustentável do Estado. Para tanto, objetivou-se criar alternativas coletivas de orientação aos agricultores familiares (assentados e quilombolas) na área de fruticultura, horticultura e sistemas agroflorestais para o uso de técnicas apropriadas no processo produtivo, demonstrando a eles a eficácia de métodos para inserção de modelos agrícolas e organizacionais na transição agroecológica, visando à autossuficiência na produção de alimentos para consumo e geração de renda.

Nesse artigo, portanto, registram-se alguns resultados desse processo educativo que vem se desenvolvendo nas comunidades dos dois assentamentos, Amparo e Lagoa Grande e na Comunidade Quilombola, especialmente, por se tratar de uma relação entre teoria e prática e entre os saberes desses agricultores familiares e a universidade. 


\section{CARACTERIZAÇÃO DAS COMUNIDADES TRABALHADAS}

A área de trabalho compreende as regiões dos assentamentos (amparo e Lagoa Grande) e de uma pequena propriedade (3ha) habitada por famílias de origem quilombola, onde suas economias estão muito dependente no desenvolvimento do setor agrícola. O município de Dourados (Figura 1) está situado geograficamente a $22^{\circ} 12^{\prime} 16^{\prime \prime}$ de latitude Sul, 5448'2" de longitude Oeste e $452 \mathrm{~m}$ de altitude média, localizada na região sul do Estado de Mato Grosso do Sul, é uma região essencialmente agrícola com predomínio de Latossolo Vermelho distroférrico, derivados do basalto, profundos e argilosos (EMBRAPA,1999), de textura argilosa e de topografia plana.

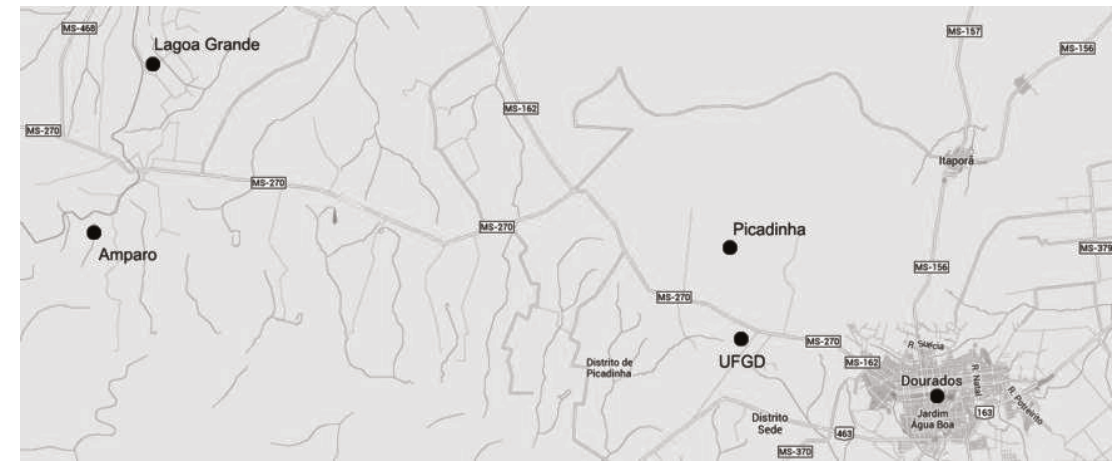

Figura 1- Mapa da região de Dourados destacando comunidades comunidade quilombola, assentamento Amparo e Lagoa Grande onde foram desenvolvidos o trabalho.

\subsection{Assentamento Amparo}

O Assentamento Amparo está localizado no distrito de Itahum, Município de Dourados, estado de Mato Grosso do Sul, distante aproximadamente $300 \mathrm{~km}$ da capital do Estado, $65 \mathrm{~km}$ da sede do município e $15 \mathrm{~km}$ do Distrito com latitude de $22^{\circ}$ e 10 minutos e longitude de $53^{\circ}$ e 20 minutos, área total de $1.126,8933$ ha, dividido em 67 lotes que variam de 15.0002 ha a 29.6319 ha, área do centro rural de 2.9998 ha e 21.0544 ha de estradas vicinais, confrontando ao Norte com Paulo Cervieri; ao Sul com Rio Dourados; Leste com Córrego Rego D'água; Oeste Arno Werner e Rio Dourados, anteriormente esta fazenda cultivava, soja, milho, feijão, aveia, trigo, etc. Foi adquirida pelo Banco do Brasil e comercializada posteriormente com o INCRA onde hoje se encontra o Projeto de Assentamento que recebe o mesmo nome da Fazenda Amparo.

As famílias que compõem o assentamento Amparo são na sua totalidade pessoas, de baixo grau de escolaridade, baixo poder aquisitivo, com pouco conhecimento tecnológico da agropecuária, mas com tradição por serem filhos de produtores rurais. Essas famílias são oriundas de diversos municípios do Estado de Mato Grosso do Sul: Bataiporã (32) Dourados (29) e Rio Brilhante (06) que são compostos na sua maioria pelo casal de um a sete filhos, com idade escolar de $1^{\circ}$ Grau. 
Antes de serem assentadas essas familias trabalhavam como arrendatários, diaristas, peões e outras atividades da agropecuária em seus respectivos municípios e tinham muitas dificuldades de sobrevivência com dignidade e de propiciar educação de qualidade aos seus filhos. Devido tal situação resolveram procurar o INCRA onde se inscreveram com a finalidade de obter um "pedaço" de terra para que dignamente pudessem criar e educar seus filhos. No dia 27 de agosto de 1997, um grupo de aproximadamente 50 famílias ocupou a Fazenda Amparo e cumprindo as determinações legais do INCRA foram assentadas no dia 31 de outubro do mesmo ano, onde hoje localiza-se o Projeto de Assentamento Amparo.

\subsection{Comunidade Quilombola}

A comunidade Quilombola está localizada no distrito de Picadinha, Município de Dourados, Estado de Mato Grosso do Sul, distante aproximadamente $258 \mathrm{~km}$ da capital do Estado e $23 \mathrm{~km}$ do município com área total de 60 ha. É constituída por 12 famílias remanescentes dos quilombos, descendentes de Dezidério Felipe de Oliveira, que, oriundo de Minas Gerais, se estabeleceu na Picadinha no ano de 1923 e adquiriu terras do Estado de Mato Grosso, antes da divisão do estado e se denominava Cabeceira São Domingos.

Essa comunidade desenvolve produção de milho, feijão, mandioca, hortaliças e criam galinhas poedeiras e frango de corte, além de cultivarem o pasto para a criação de algumas vacas leiteiras, destinadas à subsistência familiar. No seu entorno observa-se pequenos produtores chacareiros, envolvidos com atividades diversificadas em agricultura e pecuária.

Uma das características marcantes dessa comunidade é o envolvimento na "luta" por reconhecimento e legalização de suas terras, sendo que representados por um dos filhos mais velho, participam cotidianamente de ações, manifestações, reuniões e viagens a Brasília.

\subsection{Assentamento Lagoa Grande}

O Assentamento Lagoa Grande localizado no sudoeste do estado, distante $0,1 \mathrm{~km}$ do Distrito de Itahum, $65 \mathrm{~km}$ da sede do município de Dourados e $280 \mathrm{~km}$ da capital do Estado de MS, foi implantado, no ano de 1997, em terras que outrora foi de propriedade do Coronel Osvaldo Pinheiro de Almeida e posteriormente dos seus herdeiros O INCRA comprou dos herdeiros 4.111,4285 ha da Fazenda Nova da Lagoa Grande situada no Distrito de Itahum, Município de Dourados, Estado do Mato Grosso do Sul, distante $0,1 \mathrm{~km}$ do Distrito, $65 \mathrm{~km}$ da sede do município e 280 $\mathrm{km}$ da capital do Estado, com latitude de $22^{\circ}$ e $10 \mathrm{~min}$. Com longitude de $53^{\circ}$ e 20 min, confrontando no Norte: com a Fazenda Lagoa Grande e Nei Azambuja, sul: Distrito de Itahum, várias chácaras e Amilton de tal, Leste: Rodovia MS Coronel Juca de Matos, Oeste: Córrego Sucuri e Faz. Sant'Ana. Antes de ser adquirida pelo INCRA para assentamento dos parceleiros da Lagoa Grande esta Fazenda era usada para pastoreio de bovinos de forma intensiva, As famílias que compõem o assentamento Lagoa Grande são na sua totalidade filhos de produtores rurais com pouco conhecimento tecnológico, baixo grau de escolaridade e pouco poder aquisitivo. Essas famílias são descendentes de quase todo território nacional e oriundo dos municípios de: Bataiporã 61; Dourados 70; Rio Brilhante 8; e mais 12 famílias de outros municípios de Mato Grosso do Sul, totalizando 151, das quais, 20 participaram das atividades realizadas no local. As famílias de um modo geral e 
composta pelo casal, variando entre um a cinco filhos com idade escolar do Préescolar até $8^{\mathrm{a}}$ série do $1^{\circ}$ grau.

Antes de serem assentadas, essas famílias trabalhavam como arrendatários, diaristas, peões e outras atividades da agropecuária e tinham muitas dificuldades para criar e educar seus filhos. Devido tal situação procuraram o INCRA com a finalidade de conseguir um "pedaço" de terra com objetivo o desenvolvimento sócio-econômico e, garantir assim, a educação e o sustento dos seus familiares.

\section{DESENVOLVIMENTO}

O trabalho foi realizado pela Universidade Federal da Grande Dourados, com apoio da Agência de Desenvolvimento e Extensão Rural - AGRAER e Prefeitura Municipal de Dourados, com implantação de Unidades Demonstrativas (UDs), oferecendo-se oficinas, palestras e cursos teórico-prático, com orientações sobre tecnologias, condições ambientais para as plantas, formas de propagação, cuidados das plantas durante o ciclo vegetativo, etc.

A vegetação natural da região de Dourados-MS caracteriza-se pelo cerrado principalmente com fisionomias mais abertas, devido à forte antropisação ocorrida no local. São poucas as propriedades que se pode observar um estado mais conservado da vegetação, visto que a predominância é de pastagem, consequentemente a produção de leite, é a atividade principal da região. Portanto, estas informações relevam a importância climática da região, para melhor decisão sobre as escolhas das culturas que foram inseridas no local, uma vez que esta condição está presente nas comunidades envolvidas nas ações de extensão, sendo que há de modo geral, intenções desses agricultores familiares de diversificação da produção, que nesses locais exige maior atenção e muitas vezes, a correção do solo e a utilização de técnicas que tenham efeito nessas condições.

Considerando essa realidade, desde o início da execução das ações nas comunidades, foram adotados princípios agroecológicos pautados no manejo de sistemas agrícolas, buscando a conservação dos recursos naturais, como o solo, a água e biodiversidade, incorporando princípios biológicos e aproveitamento dos recursos locais, como resíduos vegetais, estercos dos animais e algumas plantas com efeitos repelentes, inseticidas ou fungicidas, procurando superar deficiências no solo.

Diante da realidade da região e das comunidades envolvidas, as atividades foram, de modo coletivo, definidas, organizadas e realizadas através de oficinas, reuniões, palestras, rodas de conversa, visita técnica no campo e, gradativamente o trabalho foi se efetivando e continua a ocorrer, haja vista que trata-se de um processo longo e contínuo, alicerçado na valorização do diálogo orientador de uma prática coletiva, não paternalista, controladora ou produtivista.

Antes de iniciar o plantio das culturas, procedeu-se a coleta de solos para análise química no laboratório de solos da Faculdade de Ciências Agrárias da UFGD, a uma profundidade de $0-20 \mathrm{~cm}$, cujos resultados são apresentados na Tabela 1.

Em virtude da alta fertilidade do solo do assentamento Amparo e Comunidade Quilombola, não foi necessário fazer calagem para elevar a saturação de base, optando pela adubação orgânica para manutenção do solo. Já no assentamento Lagoa Grande, por ser um solo altamente arenoso, foi necessário todos os procedimentos para correção do mesmo conforme descrito a seguir: calagem $\left(3 \mathrm{t}^{-h \mathrm{~h}^{-1}}\right)$ de calcário dolomítico com PRNT $80 \%$, incorporado a $20 \mathrm{~cm}$ de profundidade em toda a área, adubação com Superfostato triplo (365 kg.ha ${ }^{-1}$ ) e Cloreto de Potássio - KCl (105 kg.ha ${ }^{-1}$ ) além de NPK 4-14-8 (150g/cova) e Boro (Ácido bórico (10g/cova)) distribuídos nas covas e misturados com terra antes do plantio. 
Tabela 1 - Características químicas de amostras de solo coletadas no assentamento Amparo, Lagoa Grande e comunidade Quilombola. UFGD, Dourados, MS, 2008.

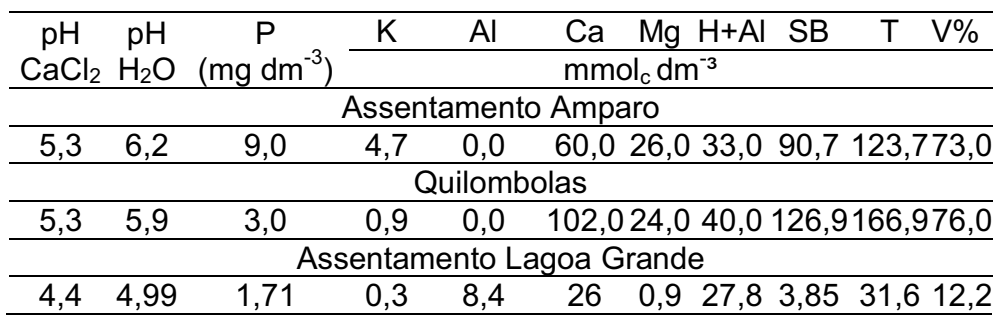

\subsection{Atividades desenvolvidas na forma de unidades demonstrativas}

\subsubsection{Fruticultura}

Essa atividade foi iniciada no assentamento Amparo e comunidade Quilombola, a partir de julho de 2008 no sistema agroecológico de produção. Inicialmente, no assentamento Amparo, foi proferida uma palestra sobre a importância de consumo e produção de frutas em pequenas propriedades. Após término da palestra, houve interesse dos participantes presentes que totalizavam 10 famílias moradoras no local, sobre o cultivo de frutíferas. Então, decidiu-se a implantação de uma UD no local e um dos participantes foi sorteado para desenvolvimento da atividade. A família contemplada cedeu uma área de $6.592 \mathrm{~m}^{2}$ de sua propriedade tendo como responsáveis todo participantes do grupo para a implantação e manutenção do pomar. Após o plantio das mudas, mesmo com área cercada, houve a entrada de gado, danificando a maioria das plantas. Para que não houvesse desânimo do grupo, decidiu-se a implantação de uma segunda UD em outra propriedade familiar, escolhidas por eles, onde foi cedida uma área de $1.464 \mathrm{~m}^{2}$, em local oposto à primeira, porém mais acessível às famílias envolvidas, uma vez que ainda havia recursos para essa finalidade.

Na comunidade Quilombola, uma vez que a maioria trabalha em emprego fixo, foi agendada uma data em que todos estivessem presentes e realizou-se uma oficina teórico-prática com o plantio das mudas e orientações necessárias no manejo durante o desenvolvimento das plantas. Nesta localidade foi instalada uma UD, numa área de $5.000 \mathrm{~m}^{2}$. Com a presença do grupo de agricultores familiares fez-se à

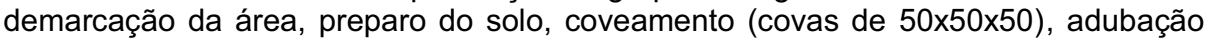
da cova e plantio das mudas. Em cada cova adicionou-se 2 litros de esterco bovino curtido, que foi misturado com o solo retirado e depois devolvido na cova e em seguida feito o plantio das mudas.

Tanto no assentamento Amparo como na comunidade Quilombola, o procedimento do plantio foi executado de acordo com as recomendações agronômicas indicadas para cada espécie. Foi destinada, de acordo com a adaptação climática e de solo em cada UD, 20 espécies de frutíferas, distribuídas em 40 variedades diferentes, totalizando em 180 plantas.

As frutíferas selecionadas de acordo com as adaptações regionais foram mangueiras - Mangifera sp (var. coração de boi, Hadem, Palmer, Kent, Keit, Tommy 
atkins e Boubom); citros - Citrus sp (laranja de mesa, natal e pêra rio, mexerica, muricota, limão itaiti e galego); abacateiro -Persea sp (var. manteiga, margarida, pollok, quintal e pélora); goiabeira - Psidium SP (branca e vermelha); nespereira Eriobotrya japonica Lindl; pessegueiro - Prunus persica L. Batsch; aceroleira Malphigia glabra L.; figueira - Fícus carica L.; caramboleira - Averrhoa carambola L; gravioleira - Annona muricata; coqueiro - Cocos nucifera; jabuticabeira - Myrciaria sp; tamarindo - Tamarindus indica L; palmito (pupunha - Bactris gasipaes Kunth e juçara Euterpe edulis), uvaia - Eugenia pyriformis; bananeira - Musa sp (var. caturra, nanica, Annona muricata e prata), cajueiro - Anacardium occidentale L; pitangueira - Eugenia uniflora $L$ e jaqueira - Artocarpus heterophyllus que foram espécies caracterizadas de interesse local e com potencial econômico. A distribuição das plantas na área de plantio foi feita de forma que as de porte maiores ficassem em posição de quebra ventos, protegendo as de portes menores ou mais sensíveis, principalmente de geadas e ventos frios.

Quinzenalmente eram feitas pulverização foliar com biofertilizante supermagro proveniente de práticas de curso realizado nas propriedades e noventa dias após plantio, fez-se adubação de manutenção incorporada ao solo ao redor das plantas, com três litros de esterco bovino curtido. Dez meses após plantio, foi realizada uma poda, dos ramos ladrões, e na ocasião, fez-se uma adubação de cobertura utilizando três litros de compostagem produzida na propriedade utilizando resíduos vegetais e estercos animais.

As mudas de frutíferas foram oriundas de viveirista comercial de Dourados, do viveiro da prefeitura municipal da cidade e da Escola Agrícola Padre Anchieta de Dourados.

Desde a aquisição das mudas até que as plantas estivessem com pegamento definitivo, as famílias eram visitadas semanalmente por professor específico da área de fruticultura, estagiários bolsistas e voluntários discentes da UFGD e técnicos da Agraer para avaliação e orientação necessária acerca dos problemas fitossanitários que porventura poderiam aparecer. Após adaptação das plantas, as visitas ocorriam quinzenalmente. Nessas ocasiões, eram proferidas palestras na forma teórico-prática, enfatizando alternativas corretas de plantio como espaçamento adequado entre plantas conforme a espécie, tipos de podas conforme necessário, adubação de manutenção e controle alternativo de pragas e doenças quando. Em locais que não houve pegamento das plantas, as mesmas foram substituídas por novas mudas. Não foi utilizado agrotóxico para controle fitossanitário.

Durante o desenvolvimento vegetativo das plantas, visando diversificar a produção na propriedade, eram cultivadas nos espaços entre as linhas, culturas como milho, feijão, berinjela, jiló, batata doce, amendoim e brócolis. Além dessas culturas, houve inclusão de algumas espécies de adubação verde como feijão de porco, guandu, crotalárias e nabo forrageiro, que eram cortadas antes do florescimento e deixadas no solo.

É importante ressaltar que toda a prática extensionista foi pautada na presença constante da equipe executora, criando situações propícias para que os agricultores familiares participassem, demonstrassem suas dúvidas, com momentos de ampla participação de todas as pessoas, inclusive de aprendizado para bolsistas que tiveram a oportunidade de relacionar os conteúdos estudados em sala de aula com a realidade concreta, envolvida por desafios sociais, econômicos e relativos à natureza. 


\subsubsection{Olericultura, plantas medicinais, aromáticas e condimentares}

Essa atividade foi desenvolvida no assentamento Amparo e na Comunidade Quilombola, a partir de maio de 2008 no sistema agroecológico de produção.

A área destinada para instalação da UD foi escolhida pelas comunidades e foi desenvolvida em propriedade familiar. A atividade constou com a participação de 10 e oito famílias para a comunidade Amparo e Quilombolas, respectivamente. A área destinada ao desenvolvimento da UD foi de $400 \mathrm{~m}^{2}$ e de $2000 \mathrm{~m}^{2}$ do assentamento Amparo e comunidade Quilombola, respectivamente.

As atividades foram realizadas na forma de curso teórico-prático enfatizando o preparo do solo, formação de canteiros, calagem, resíduos orgânicos (compostagem), biofertilizante foliar, húmus, caldas, semeadura, plantio, transplante, desbaste, cobertura do solo, irrigações, capinas, colheita, beneficiamento e escoamento da produção. Nas UDs foi destinado um local definitivo de $50 \mathrm{~m}^{2}$ para as plantas medicinais, aromáticas e condimentares e o restante da área foi trabalhado na forma de rotação de culturas entre as espécies, consórcio e utilização de adubação verde (feijão de porco, guandú, crotalárias, nabo forrageiro e mucunas), durante o pousio dos canteiros, com o intuito de demonstrar aos agricultores a importância da biodiversidade em pequena área.

Inicialmente a área foi preparada com uma aração e uma gradagem, uma vez que o local era constituído de pastagem, sendo necessário esse procedimento Em seguida, confeccionou-se os canteiros manualmente com o uso de enxadas no assentamento Amparo e com rotoencanteirador na comunidade Quilombola e fez-se a adubação nas duas áreas conforme descrito abaixo. Nas áreas de pousio que foi cultivada plantas para adubação verde, as mesmas foram roçadas no início do florescimento e deixadas sobre o solo por tempo indeterminado, e depois incorporado ao mesmo no momento da confecção dos canteiros.

Inicialmente a adubação foi realizada com estercos bovinos (10 t.ha- ${ }^{1}$ ), apenas para manutenção do solo e posteriormente a partir de 120 dias após início das atividades, optou-se pela compostagem, que é um adubo orgânico obtido a partir de restos de culturas e dejetos animais, quando estas já estavam bem decompostos. $O$ composto orgânico foi preparado da seguinte forma: 3 camadas alternadas de $30 \mathrm{~cm}$ de resíduos vegetais secos e frescos triturados ou não, intercalados, intercalados com $200 \mathrm{~g}$ de fosfato natural, $5 \mathrm{~cm}$ de estercos bovino, cama de frango, esterco de carneiro e de coelho e carvão vegetal, adquiridas nas propriedades dos produtores e parte cedida pela UFGD. O composto formado contou com uma altura de $1 \mathrm{~m}$, sendo umedecida e revirada quando a temperatura estava elevada o que ocorria entre sete a dez dias. Em torno de 120 dias o material já estava completamente decomposto pronto para uso. Além do composto, foi preparado o húmus utilizando um litro de minhocas (Eisenia foetida), cedidas pela Embrapa CPAO de Dourados, por $\mathrm{m}^{3} \mathrm{de}$ esterco fresco de bovino.

Quinzenalmente utilizava-se adubação foliar, com o biofertilizante supermagro, na dosagem de 5 a $10 \%$ conforme a exigência das espécies, preparado durante a realização de cursos e oficinas, utilizando os macronutrientes (Cloreto de cálcio, Sulfato de magnésio e Enxofre) e os micronutrientes (Ácido bórico, Molibdato de sódio, Sulfato de cobalto, Sulfato de cobre, Sulfato ferroso, Sulfato de manganês, e Sulfato de zinco), cinzas, açúcar mascavo e leite. Após 30 dias, o líquido foi coado e armazenado em garrafas pet de 2 litros.

Para o plantio, foi realizada semeadura direta (em local definitivo) e indireta em bandejas de isopor com células, ou sementeiras em canteiros preparados para esse fim, conforme as indicações das espécies, onde foram feitas repicagens das plântulas que germinaram em alta população deixando somente a mais vigorosa para posterior plantio em local definitivo. 
Dentre as espécies de hortaliças que foram cultivadas, cita-se a berinjela, jiló, alface, almeirão, chicória, repolho, couve comum, couve-flor, abóboras, cebola, cebolinha, salsinha, brócolos, cenoura, beterraba, feijão vagem, pepino, quiabo, rabanete, coentro e rúcula, utilizando-se sementes oriundas do mercado local.

As seguintes plantas medicinais aromáticas e condimentares foram inseridas para serem cultivadas no local: manjericão (Ocimun basilicum), manjerona (Origanum majorona), tomiho (Tymus vulgaris), hortelã (Mentha $s p)$, sálvia (Salvia oficinalis), alecrim (Rosmarinus officinalis), Camomila (Matricaria chamomilla), losna (Artemisia absinthum), arnica (Solidago microglosa), confrei (Symphytum officinale L.), citronela (Cymbopogon nardus), capim cidreira (Cymbopogon citratus), melissa (Melissa officinalis), cidró/erva-luísa (Aloysia triphylla), cânfrinho (Mentha canforata), segurelha (Satureja montana L.), anador (Justícia pectoralis), mil folhas (Achillea millefolium), pulmonária, bardana (Arctium lapa), com mudas oriundas do horto de plantas medicinais da UFGD. Todas as plantas medicinais, aromáticas e condimentares foram identificadas conforme nomenclatura botânica.

As irrigações foram feitas utilizando o sistema de aspersão (santeno) conforme necessidade das culturas. Para esta etapa, no Assentamento Amparo foi concedida uma bomba análgera que foi imersa na água do posso, com 10 metros de profundidade, para condução de água até uma caixa d'água suspensa a uma altura de 3 metros de altura do solo com uma capacidade de 1000 litros, com 50 metros de distância do local a ser irrigado e na Comunidade Quilombola foi adquirido uma roda d'água via projeto, e esta leva água até uma caixa d'água com capacidade de 10.000 litros, localizada 100 metros distante do local que foi feita a implantação da UD, por meio de canalização da água para esse destino.

As plantas invasoras foram controladas mediante capina e arranquio sempre que necessário.

Para o controle de pragas e doenças, as famílias foram orientadas a utilizar biofertilizante e defensivos naturais como caldas de alho (Allium sativum), cebolinha (Allium cepa) pimentas e nim (Azadirachta indica), triturados em liquidificador, além de chá de losna (Artemisia absinthum), camomila, etc.

\subsubsection{Sistemas Agroflorestais}

Os sistemas agroflorestais (SAF) caracterizam-se pelo consórcio entre componentes animais, culturas agrícolas e/ou plantas lenhosas, visando a sustentabilidade, conforme Silva et al. (2010), que demonstraram diversos conceitos aplicados na literatura. Os SAF podem ser distribuídos em três sub-sistemas: silvipastoril (silvicultura e animais), agrissivipastoril (culturas agrícolas, animais e plantas lenhosas) e o agrissilvicultural (culturas agrícolas e plantas lenhosas).

Os SAF foram implantados no assentamento rural Lagoa Grande, por meio de unidades demonstrativas (UD) utilizando sub-sistema agrissilvipastoril, tendo como componente arbóreo o eucalipto integrado com gado leiteiro.

Para definição comunitária a respeito dos sistemas a serem implantados primeiramente foi realizada uma palestra onde foram expostos os conceitos sobre o tema, as diferentes composições de espécies animais e vegetais para os SAF, vantagens, desvantagens e análise econômica. Após explanação do assunto, vários produtores participantes do evento se interessaram em implantar o sistema. $\mathrm{Na}$ ocasião estavam presentes 22 participantes. Então decidiu-se pela realização de um sorteio entre eles e três foram contemplados para a instalação das UDs em dois há de seus lotes. 
Em seguida analisaram-se os solos dos lotes, caracterizados então como Latossolo Vermelho distrófico textura média (LVd). A partir da análise de solos (Tabela 1) decidiu-se pela calagem $\left(3\right.$ t.ha $\left.^{-1}\right)$, supertriplo e Cloreto de potássio conforme citado acima.

Para o plantio florestal, foram utilizadas mudas de eucalipto híbrido urograndis, plantadas no quarto trimestre de 2008 nas três propriedades contempladas, com apoio dos grupos participantes. O espaçamento utilizado foi de 9 $\mathrm{m}$ nas entrelinhas e $4 \mathrm{~m}$ entre plantas. O prepara do solo foi o convencional.

Foi aplicado gel nas covas para melhorar a retenção de umidade e consequente sobrevivência das plântulas, em função do baixo nível de precipitação (Figura 2) e alta temperatura (Figura 3) na época do plantio. Foi necessário irrigar via regador com capacidade de 5 litros, duas vezes ao dia, até que as plantas apresentassem condições de sobreviver.

Os agricultores foram orientados a cultivar outras culturas nas entre linhas até que as plantas tivessem altura suficiente para plantação da pastagem.

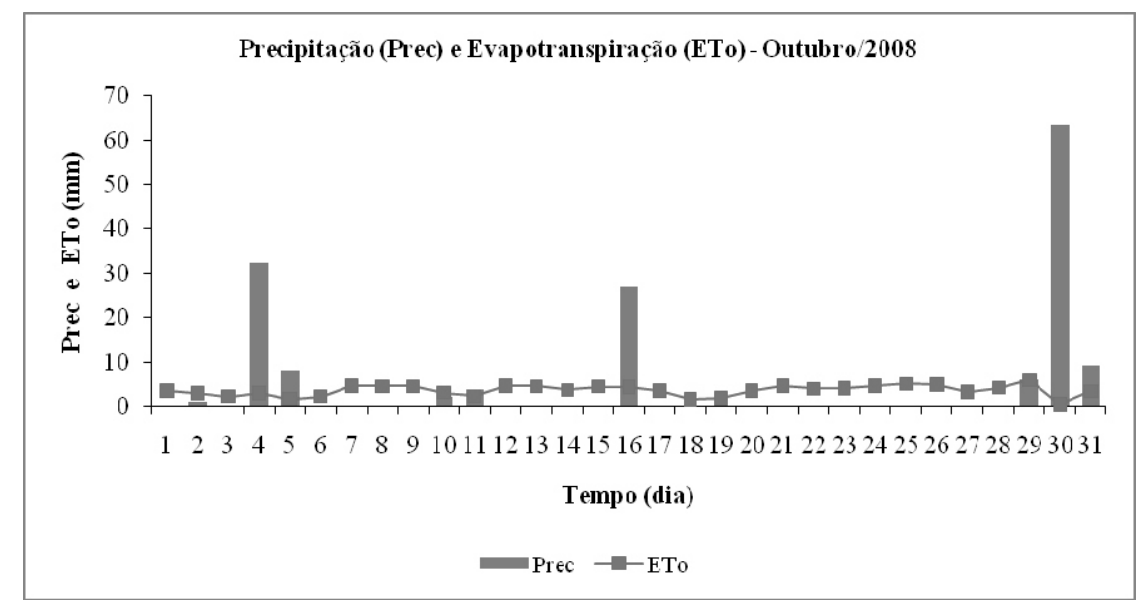

Figura 2 - Precipitação e evapotranspiração ocorrida na época do plantio de eucalipto no assentamento Lagoa Grande 


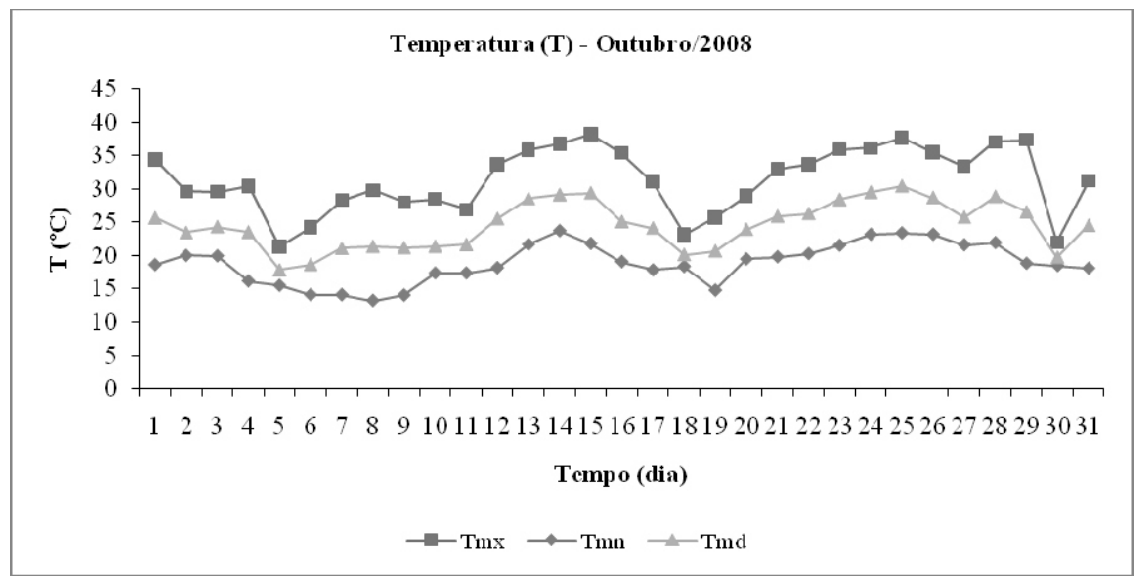

\section{Figura 3 - Temperaturas ocorrida na época do plantio de eucalipto no assentamento Lagoa Grande}

Os agricultores foram orientados a cultivar outras culturas nas entrelinhas até que as árvores atingissem altura suficiente para a introdução das forrageiras, tais como: melancia, abóbora, amendoim e mandioca.

Por opção de cada um os sistemas foram distribuídos da seguinte forma: a) em um dos lotes permitiu-se a revegetação de gramíneas forrageiras do gênero Urochloa anteriormente existente na área do plantio florestal, atendendo a aptidão pecuária da região, especificamente leiteira; b) em outro lote as mudas foram plantadas em área com vegetação remanescente de cerrado, priorizando a preservação natural do local; d) no lote do terceiro sorteado foi trabalhado o consórcio de culturas agrícolas. Em todos os casos foi realizado o controle de formigas cortadeiras quando necessário, bem como a capina ao redor das plantas num raio de um metro.

Após o plantio das mudas de eucalipto a região foi penalizada por um veranico de 55 dias, resultando no replantio de grande parte das mudas. Quando as plantas alcançaram em torno de um metro de altura, em agosto de 2009 , foi realizada uma adubação de cobertura para superar a queda no desenvolvimento em função de forte seca na época de plantio, com $36 \mathrm{~g}$ de $\mathrm{KCl}, 22 \mathrm{~g}$ de uréia e 28 gramas de superfosfato simples, distribuídos em duas covetas laterais a cada planta nos três lotes beneficiadas.

Em dezembro de 2009, por meio de uma visita técnica, os agricultores foram orientados sobre os procedimentos de desrama e detectou-se a necessidade de outra adubação de manutenção, principalmente em algumas plantas com desenvolvimento comprometido. Durante o desenvolvimento das plantas as UD eram visitadas, de 30 em 30 dias, pelos profissionais e extensionistas para verificar o desenvolvimento das plantas.

As avaliações foram tabuladas e analisadas por meio de estatística descritiva.

Todas as atividades tiveram parcerias financiadas do CNPq, MEC e UFGD. 


\section{RESULTADOS E DISCUSSÃO}

Os locais trabalhados compreendem regiões predominantes da agricultura familiar onde suas economias estão dependentes no desenvolvimento do setor agrícola, sendo que a pecuária leiteira sempre foi a principal atividade econômica desenvolvida por eles.

Ao conhecer a realidade atual dos assentamentos e comunidades quilombolas, observou-se uma necessidade geral de inserção de atividades agrícolas e de criação de animais diversificadas. E mais, detectou-se o anseio pelo acompanhamento de profissionais técnicos da área de extensão, que os auxiliassem na preservação do meio ambiente, na implantação de atividades que promovesse a agregação familiar, bem como a redução no uso agrotóxicos. Consequentemente, demonstraram interesse em novas alternativas de renda e aproveitamento alimentar, resgatando costumes antigos e naturais.

As ações executadas nas propriedades por meio das UDs permitiram detalhar o perfil dos agricultores que residem em pequenas áreas, especialmente no que se refere aos hábitos de consumo alimentar, de produção agrícola e suas expectativas relacionadas ao uso de inovações tecnológicas no campo.

Como esperado em qualquer ação de transição para a agroecologia, várias dificuldades foram surgindo principalmente relacionado com a insegurança e a incerteza dos resultados que o modelo agrícola pode proporcionar, pois normalmente as pessoas fazem aquilo que estão acostumadas, sentindo-se mais seguras. Essa mudança não ocorre de imediato, Trata-se de uma reeducação para a agricultura, da maneira de ver e lidar com a propriedade rural (PADOVAN, 2007).

Observou-se também o espírito da individualidade e competição entre as famílias, além da variação climática que ocorreu na epoca em que iniçiou-se as atividades, o que propiciou um atraso no desenvolvimento inicial das plantas. Esses fatores influenciaram no desenvolvimento das atividades, conforme a programação elaborada.

Assim, puderam ser identificados os principais problemas e expectativas das famílias agricultoras, permitindo propor ações que podem melhorar a vida familiar no campo, a permanência dos jovens na propriedade rural, além de oferecer alternativas de sistemas de produção agroecológicas para a região.

As quantidades de cursos, palestras e visitas técnicas realizadas durante as atividades extensionistas nas comunidades são apresentadas conforme a Tabela 2.

Tabela 2 - Ações desenvolvidas de fruticultura (F), horticultura (H) e sistema agroflorestais (SAFs) entre o perído de 2008 a 2010.

\begin{tabular}{llllllllll}
\hline $\begin{array}{l}\text { Ação/ } \\
\text { Atividade }\end{array}$ & \multicolumn{2}{l}{$\begin{array}{l}\text { Assentamento } \\
\text { Amparo }\end{array}$} & \multicolumn{4}{c}{$\begin{array}{c}\text { Assentamento } \\
\text { Lagoa grande }\end{array}$} & \multicolumn{3}{c}{$\begin{array}{c}\text { Comunidade } \\
\text { Quilombola }\end{array}$} \\
\hline & $\mathrm{F}$ & $\mathrm{H}$ & SAFs & $\mathrm{F}$ & $\mathrm{H}$ & SAFs & $\mathrm{F}$ & $\mathrm{H}$ & SAFs \\
\hline Cursos & 1 & 3 & 0 & 0 & 0 & 1 & 1 & 3 & 0 \\
$\begin{array}{l}\text { Palestras } \\
\text { Visitas }\end{array}$ & 1 & 4 & 1 & 0 & 0 & 1 & 1 & 4 & 0 \\
técnicas & 24 & 81 & 0 & 0 & 0 & 26 & 24 & 81 & 0 \\
\hline
\end{tabular}

Essas ações permitiram melhor interação com as famílias que estão no campo, esperando por oportunidades de aprendizado e capacitação relacionados com as atividades, despertando interesse em alguns que deram prosseguimento nas 
atividades do modelo agroecológico e fuga de outras pessoas que preferiram continuar no modelo convencional.

\subsection{Perfil das famílias assentadas}

Das 35 famílias envolvidas, a maioria era constituída do sexo masculino, em torno de $82,2 \%$, enquanto que do sexo feminino, apenas $17,8 \%$ se envolveram nas atividades. Dentre esses, 93,7\% eram chefe de família com idade entre 35 e 60 anos e 5,9\%, constituía-se de jovens com faixa etária de 14 a 26 anos. Entre adultos, 3,2\% eram aposentados e/ou pensionista. Entre essas famílias, detectou-se que a renda familiar mensal variavam entre 0,5 a 2 salários mínimos mensal.

\subsection{Olericultura}

No assentamento Amparo, depois da implantação da UD, houve uma dispersão do grupo, sendo necessária, a formação de novo grupo. Algumas pessoas pemaneceram e como houve interesse de outras famílias que se uniram deu-se a continuidade do trabalho. As produções obtidas durante o desenvolvimento do trabalho foram distribuídas igualmente entre todos os participantes e o excedente comercializado dentro do assentamento e no restaurante universitário da Universidade Federal da Grande Dourados.

$\mathrm{Na}$ Comunidade quilombola, por se localizar próximo a área urbana, desde o início das atividades, à medida que houve excedente de produção, as famílias foram incentivadas a comercialização dos produtos, semanalmente, em espaço cedido dentro da universidade (UFGD), em uma feira organizada pelo projeto de incubadora, desenvolvido pela faculdade de ciências humanas $(\mathrm{FCH})$, e trabalha com a parte social das famílias do campo.

Como o sistema de produção foi conduzido utilizando alternativas naturais como compostagem, biofertilizante e caldas obtendo boa resposta, os produtos foram oferecidos de forma a divulgar as possibilidades de obter produção sem uso de agrotóxicos, minimizando o impacto ambiental. Para Valarini et al. (2011) as práticas agrícolas tais como preparação mecanizada e intensiva e a falta de cobertura do solo, a ausência de rotação de culturas com diferentes sistemas radiculares e o baixo uso de adubação verde proporciona degradação do solo. Desta forma, pode se verificar que a produção das hortaliças obtida proporcionou ao grupo participante o aprendizado das técnicas de produção de hortaliças de forma ecológica além de beneficiar as famílias com alimentos saudáveis.

Resultados contrários são descritos por Ferreira et al. (2011) em estudos com vários tipos de adubação orgânica avaliadas nas doses de 5,10 e $15 \mathrm{t}$ ha-1 (base seca) com a cultura do rabanete detectaram que o preparo convencional do solo expressou resposta linear às doses de composto e a utilização do plantio direto sobre palhada de plantas espontâneas, independente da dose de composto, promoveram maiores produtividades e massa fresca de raiz comercial, que o plantio direto quando utilizado a cobertura viva com amendoim forrageiro e de plantas espontâneas.

No entanto, para Zuba et al. (2011) o emprego de adubos orgânicos e minerais reduziu significativamente a incidência de podridão bacteriana e o ataque de pragas no tomateiro em relação aos adubos químicos. Esta comparação com resultados de efeito de adubação ilustra a meta alcançada com uso de insumos naturais. 
Observou-se também por meio de acompanhamento constante, mais união e valorização do trabalho coletivo por meio da participação das famílias dos assentados acrescidos pelo aumento da participação dos filhos no contexto familiar. De acordo com Buainain et al. (2003), o desempenho da agricultura familiar reflete um conjunto amplo de condicionantes, desde a disponibilidade de recursos, a inserção socioeconômica, a localização geográfica, as oportunidades e a conjuntura econômica, as instituições e valores culturais da família, do grupo social e até mesmo do país.

A ocorrência de pragas e doenças nas plantas cultivadas durante a condução do projeto, principalmente na fase inicial, também se constituiu num grande desafio, pois o manejo convencional de áreas adjacentes geralmente favorece o aumento da população desses organismos, devido ao uso constante de agroquímicos que causam desequilíbrio na natureza. Dentre as pragas observadas, citam-se vaquinhas (Diabrótica speciosa), curuquerê da couve (Ascia monuste orseis), cochonilhas (Icerya purchasi, Planococcus citri) trips sp, pulgões (Brevicoryne brassicae), percevejos (Pachylis pharaonis Euchistos heros, Pachicorisem torridus, Edessa meditabunda, Thyanta perdictor, e Oebalus poecilus) e as doenças observadas foram oídio (Sphaerotheca fugilinea), em abóboras e quiabo, Cercosporiose em alface, e Alternaria sp em cebola. O problema foi controlado com a utilização de protetores de plantas, isto é, biofertilizante supermagro, calda bordaleza e extratos vegetais a base de alho, cebolinha, nim, etc, além disso, incluiu-se uso de compostagem, adubos verdes e urina curtida de vaca que fornece nitrogênio para as plantas e tem ação repelente de insetos. Esse procedimento foi orientado na forma de curso teórico prático. Com o ambiente mais equilibrado, a incidência de pragas diminuiu e observou-se nível de controle satisfatório e os produtores têm demonstrado grande capacidade de enfrentar os desafios na transição agroecológica.

Dentro deste contexto, Burg e Mayer (2001) citam que a urina de vaca contém fenóis que são substâncias que aumentam a resistência nas plantas e age como repelentes de insetos e controle de doenças provocadas por fungos, o biofertilizante atua como defensivo natural inibindo o crescimento de fungos e bactérias causadores de doenças e também aumenta a resistência contra insetos e ácaros.

De acordo com Souza e Rezende (2006), a utilização de composto orgânico nas adubações produz múltiplos efeitos sobre o solo e as plantas cultivadas, através do aumento da permeabilidade do solo, agregação das partículas minerais, fornecimento de macro e micronutrientes, correção da acidez, incremento na população de microorganismos e elevação da eficiência na absorção de nutrientes e as funções da adubação verde.é de proteger o solo das chuvas de alta intensidade, manter elevada a taxa de infiltração de água no solo, promover grande e contínuo aporte de fitomassa, de maneira a manter ou até mesmo elevar, ao longo dos anos, o teor de matéria orgânica do solo, melhora a condição biológica, propriedades físicas e químicas do solo, diminui a lixiviação de nutrientes e alguns adubos verdes apresenta potencial de utilização múltipla, podendo ser utilizada na alimentação animal, humana e na produção de madeira e carvão vegetal.

Conforme Primavesi (2002), além do aspecto ecológico do solo, o sistema orgânico mostra-se como alternativa viável para cultivo agrícola de hortaliças levandose em consideração também os aspectos econômicos.

Desta forma, através da observação do comportamento das famílias que participaram das ações, pode se verificar que a produção das hortaliças obtida proporcionou ao grupo o aprendizado das técnicas de produção de hortaliças de forma ecológica além de beneficiar as famílias com alimentos saudáveis além do melhor convívio local entre elas. Essas constatações ocorreram no dia a dia, no 
contato direto com os agricultores familiares que dialogavam constantemente com a equipe, e ainda, destacaram esses benefícios verificados em sua própria prática de produção. Perceberam ainda, que as hortaliças apresentavam qualidade superior daquelas que antes produziam, e ainda, muitos desses agricultores entregaram seus produtos para a merenda escolar, e verificaram que produtos orgânicos são mais valorizados e procurados, especialmente quando participam de programas governamentais. Um quilombola, afirma ter parceria com as lagartas, pois divide sua produção com elas, mesmo assim, não deixa de produzir hortaliças organicamente.

Lago et al. (2006) realizaram um estudo de casos com nove agroindústrias familiares orgânicas e citam que apesar dos avanços na agricultura orgânica nos últimos anos, associados ao intenso trabalho de cooperação e parcerias das entidades e dos agricultores familiares envolvidos, muitos problemas ainda necessitam serem enfrentados. Dentre eles destacam-se: controle de pragas e estiagem, regulamentação dos produtos orgânicos, falta de pesquisa nesta área, falta de linhas de crédito específica, falta de mão-de-obra especializada, inclusão dos produtos na merenda escolar, legislação (inspeção municipal, que proíbe atuar em outros municípios) e a falta de orientação, informações adequadas ao consumidor de produtos orgânicos, além de incentivos governamentais para torná-los, cada vez mais, acessíveis economicamente.

Os mesmos autores citam que a vantagem estratégica estabelecida pela diferenciação dos produtos orgânicos foi e é uma dos grandes impulsionadores deste setor que vem crescendo a uma taxa média em torno de $20 \%$ ao ano no Brasil e no mundo; e atentos a este crescimento do mercado, bem como nas particularidades e necessidades do mercado consumidor destes produtos, é que se estabelece a necessidade e a importância de construção de um olhar integrado ao marketing a este setor e que ao analisar a agricultura familiar produtora e comercializadora de produtos orgânicos. No caso estudado, percebe-se que a sua principal vantagem competitiva está vinculada à diferenciação dos produtos comercializados. Diferenciação esta que pode melhorar estas ações ainda bastante incipientes, presentes nas agroindústrias estudadas.

Com o desenvolvimento das atividades obteve-se as perspectivas alcançadas no quesito produção de hortaliças na agricultura familiar, considerando um incremento na alimentação das famílias e comercialização do excedente, dentro da própria comunidade e em feiras externas. Um dos entraves encontrados pelos produtores foi a problemática de comercialização, relacionado ao diferencial de valor de produtos orgânicos, como falta de conscientização do consumidor em pagar o preço válido, tendo que comercializar pelo valor dos produtos convencionais. De acordo com Lago et al. (2006), apesar dos avanços na agricultura orgânica nos últimos anos, associados ao intenso trabalho de cooperação e parcerias das entidades e dos agricultores familiares envolvidos, muitos problemas ainda necessitam serem enfrentados. Esses autores citam que estes problemas são de ordem tecnológica, comercial e política.

As espécies que tiveram maior produção e aceitação pelo consumidor foram alface, cenoura, couve, beterraba e almeirão, com colheita semanal de acordo com a Tabela 3. 
Tabela 3 - Produção de Olerícolas mais consumidas pelas comunidades e comercializadas em feiras externas.

\begin{tabular}{|c|c|c|c|c|}
\hline $\begin{array}{c}\text { Nome comum e Nome } \\
\text { científico }\end{array}$ & Unid & $\begin{array}{r}\text { Produção } \\
\text { Semana } \\
\end{array}$ & $\begin{array}{c}\text { Consumo } \\
\text { (Unid) }\end{array}$ & $\begin{array}{l}\text { Excedente } \\
\text { (Unid) }\end{array}$ \\
\hline Alface - Latuca sativa & Pé & 20 & 5 & 15 \\
\hline Almeirão - Cichorium intibus & Pé & 20 & 3 & 18 \\
\hline Beterraba Beta vulgaris & $\begin{array}{c}\text { Raiz } \\
\text { kg }\end{array}$ & 15 & 3 & 12 \\
\hline $\begin{array}{l}\text { Cebolinha - } \\
\text { schoenoprasum }\end{array}$ & $\begin{array}{l}\text { Folhas } \\
\text { masso }\end{array}$ & 18 & 2 & 16 \\
\hline Cenoura - Daucus carota & $\begin{array}{l}\text { Raíz } \\
\text { kg }\end{array}$ & 15 & 3 & 12 \\
\hline $\begin{array}{l}\text { Chicória/ } \\
\text { Escarola - } \\
\text { Cichorium endívia }\end{array}$ & Pé & 15 & 3 & 12 \\
\hline $\begin{array}{l}\text { Coentro - Coriandrum } \\
\text { sativum }\end{array}$ & Folhas & 15 & 2 & 14 \\
\hline $\begin{array}{l}\text { Couve - Brassica oleracea } \\
\text { var. acephala }\end{array}$ & $\begin{array}{l}\text { Folhas } \\
\text { masso }\end{array}$ & 25 & 4 & 21 \\
\hline $\begin{array}{ll}\text { Rabanete } & \text {-Raphanus } \\
\text { sativus } & \end{array}$ & $\begin{array}{l}\text { Raiz } \\
\text { kg }\end{array}$ & 10 & 2 & 8 \\
\hline Rúcula - Eruca sativa & Masso & 20 & 4 & 16 \\
\hline Salsinha - P. crispum (Mill.) & Folhas & 18 & 2 & 16 \\
\hline
\end{tabular}

Aquelas de produção anual também tiveram boa aceitação conforme Tabela 4. 
Tabela 4 - Hortaliças de produção anual inseridas nas comunidades familiares.

\begin{tabular}{|c|c|c|c|}
\hline $\begin{array}{l}\text { Nome comum } \\
\text { Nome científico }\end{array}$ & $\begin{array}{l}\text { Produção } \\
(\mathrm{Kg})\end{array}$ & $\begin{array}{c}\text { Consumo } \\
(\mathrm{Kg})\end{array}$ & $\begin{array}{l}\text { Excedente } \\
(\mathrm{Kg})\end{array}$ \\
\hline Abóboras -Cucurbita spp & 10 & 5 & 5 \\
\hline $\begin{array}{l}\text { Berinjela } \\
\text { melongena }\end{array}$ & 10 & 4 & 6 \\
\hline Brócolis - Brassica oleracea & 10 & 4 & 6 \\
\hline Cebola - Allium cepa & 20 & 10 & 10 \\
\hline $\begin{array}{l}\text { Couve flor - Brassica } \\
\text { oleracea }\end{array}$ & 10 & 2 & 8 \\
\hline $\begin{array}{l}\text { Feijão vagem - Phaseolus } \\
\text { vulgaris } L\end{array}$ & 15 & 5 & 10 \\
\hline Jiló - Solanum gilo & 10 & 2 & 8 \\
\hline Pepino - Cucumis sativus & 20 & 5 & 10 \\
\hline $\begin{array}{l}\text { Quiabo - Abelmoschus } \\
\text { esculentus }\end{array}$ & 25 & 10 & 15 \\
\hline $\begin{array}{l}\text { Repolho - Brassica oleracea } \\
\text { var. Capitata }\end{array}$ & 12 & 2 & 10 \\
\hline $\begin{array}{l}\text { Tomate cerejinha }-L . \\
\text { esculentum }\end{array}$ & 20 & 3 & 17 \\
\hline
\end{tabular}

Diante, de tal situação, observa-se que o cultivo e a comercialização direta das hortaliças, nas condições atualmente existentes na agricultura familiar da região, não conseguem proporcionar uma renda agrícola estável a esses agricultores.

Em relação às atividades exercidas pelas famílias, a princípio observou-se que antes do envolvimento do trabalho era apenas a produção de leite alcançando $100 \%$. Quanto à produção de hortaliças e de frutíferas, apenas em torno de $2 \%$ das famílias tinham para consumo da família. Conforme Filgueira (2003), o nível de consumo de hortaliças relaciona-se não só com a renda pessoal, que, por sua vez, depende do progresso geral de um país, como também com o grau de escolaridade e de cultura geral de sua população.

\subsection{Plantas medicinais, aromáticas e condimentares}

Considerando o uso de medicamentos a base de ervas medicinal, como parte da cultura regional, o cultivo destas plantas foi incluído após por solicitação das famílias. Com isso, puderam adquirir conhecimentos, através de cursos, quanto aos cuidados na manipulação e uso de plantas e sua classificação botânica, proporcionando assim a diminuição do extrativismo. Através das aulas práticas de preparo artesanal de fitoterápicos, as famílias passaram a produzir temperos, vinagres aromáticos e xaropes. Esses eram utilizados pela própria família ou visinhos que solicitavam. As plantas cultivadas na propriedade e mais utilizadas foram as condimentares como mangerona, manjericão, alecrim, etc. Tabela 5. 
Tabela 5 - Plantas medicinais e condimentares cultivadas no assentamento Amparo e comunidade Quilombola, na região de Dourados-MS.

\begin{tabular}{llcc}
\hline \multicolumn{1}{c}{ Variedades } & \multicolumn{1}{c}{ Nome científico } & $\begin{array}{c}\text { Consumo } \\
\%\end{array}$ & Processada \% \\
\hline Mangerona & Origanum majorana & 10,8 & 16,8 \\
Mangericão & Ocimum basilicum & 10,6 & 15,8 \\
Boldo & Pneumus boldo & 10,4 & 0 \\
Alecrim & Rosmarinus officinalis & 8,7 & 14,6 \\
Citronela & Cymbopogom nardus & 6,2 & 9,8 \\
Sálvia & Salvia officinalis & 7,8 & 13,8 \\
Tomilho & Tymus vulgaris & 7,6 & 12,5 \\
Capim cidreira & Cymbopogom citratus & 7,4 & 0 \\
Guaco & Mikania glomerata & 8,6 & 11,9 \\
Sabugueiro & Sambucus nigra & 5,9 & 8,9 \\
Hortelã & Mentha piperita & 5,7 & 8,7 \\
Poejo & Mentha pulegium & 5,6 & 7,9 \\
Carqueja & Baccharis trimera(Lees) & 3,9 & 5,6 \\
Cidró & & & \\
Arnica & Lippia citriodora & 5,8 & 0 \\
Outros & Solidago microglosa & 4,2 & 0 \\
\hline
\end{tabular}

Ao visitar as propriedades antes do desenvolvimento das atividades, foi observada que em $66,3 \%$ das propriedades havia pequenos espaços com algumas plantas desta categoria como hortelã (Mentha $s p$ ), carqueja (Baccharis trimera), boldo (Coleus barbatus), capim cidreira (Cymbopogon citratus), mangerona (Origanum majorona). De acordo com Correa Júnior et al, (2006), a grande maioria das famílias tem alguma planta medicinal cultivada em sua horta caseira, para qualquer eventualidade. Costa e Mayworm (2011) observaram que o conhecimento medicinal das plantas, na comunidade, vem sendo adquirido e transmitido de geração a geração por familiares $(58 \%)$, amigos e vizinhos $(38 \%)$ e através da literatura e meios de comunicação $(4 \%)$. E que a utilização das plantas medicinais pela maioria das pessoas foi relacionada à precariedade do sistema de saúde da cidade, ou à distância para buscar atendimento médico. Para Albertasse et al. (2010), embora o emprego das plantas com fins terapêuticos ainda seja parte importante do cotidiano de grande parte das pessoas, existem outras opções disponíveis de tratamento e a escolha de uso entre cada tratamento é feita com base na necessidade de urgência de efeitos e na disponibilidade de cada um, seja pela sazonalidade das plantas ou custo de compra do medicamento.

As ervas aromáticas e condimentares também são utilizadas com freqüência no preparo de alimentos dando-Ihes aroma, sabor e aspecto mais agradável, além de ajudar na sua conservação.

No entanto, vale ressaltar que as plantas medicinais têm sido alvo de interesse de produção com enfoque comercial na região.

A idéia de trabalhar com hortaliças e plantas medicinais aromáticas e condimentares busca resgatar costumes tradicionais, como o uso de chás, xaropes e temperos e que pode contribuir substancialmente para o desenvolvimento rural sustentável. 


\subsection{Fruticultura}

Houve poucas mortes de plantas nas duas comunidades trabalhadas, fator esse favorecido com a época de plantio que ocorreu precipitação suficiente para estabilização das mudas, havendo desenvolvimento das mesmas conforme previsto.

As que não resistiram, foram substituídas por novas mudas. Já no Assentamento Amparo, na primeira unidade, as plantas foram mais penalizadas principalmente no período de seca, sendo necessário o replantio de quase todas, em torno de $80 \%$.

$\mathrm{Na}$ segunda unidade de $1485 \mathrm{~m}^{2}$, houve melhor pegamento das plantas, provavelmente devido a maior precipitação na época do plantio ou mais dedicação por parte do grupo envolvido. Essas plantas ainda não iniciaram a produção o que deve ocorrer a partir do $3^{\circ}$ ao $5^{\circ}$ ano de plantio, dependendo da espécie de frutífera. Em torno de trinta e seis meses após o plantio das mudas, observou-se o primeiro florescimento de algumas espécies frutíferas como pessegueiro e mangueiras.

Ferreira et al. (2003), analisaram a importância do cultivo de diversas espécies de frutíferas como alternativa para o aumento de renda da agricultura familiar com as comunidades e concluíram que o maracujazeiro, a goiabeira e a pinha foram identificadas como as melhores alternativas para os produtores familiares, espécies essas utilizadas no processo de implantação nas UDs.

O uso de composto orgânico no solo e do biofertilizante super magro e caldas preventivas via foliar propiciaram o bom desenvolvimento vegetativo das plantas nos primeiros anos após implantação, não sendo necessário uso de adubos químicos e produtos para controle fitossanitário. Auler et al. (2011) estudando a ocorrência do declínio dos citros no polo citrícola da região noroeste do Estado do Paraná, em pomar experimental, observaram os sintomas da primeira ocorrência da doença aos sete anos após o plantio, e aos quinze anos atingiu $31 \%$ das plantas. Andrade et al. (2010), observaram que o uso de calda sulfocálcica, apesar de ser capaz de reduzir a população do ácaro-da-leprose abaixo do nível de controle após as aplicações, não foi capaz de reduzir a população a zero, como constatado nos tratamentos com spirodiclofen e cyhexatin. Além disso, a frequente aplicação de calda sulfocálcica pode ter aumentado a frequência de ácaros resistentes, tanto a dos ácaros-praga como a dos predadores, explicando, em parte, a maior ocorrência dos ácaros predadores nos tratamentos com aplicações sucessivas de calda sulfocálcica. No entanto a calda sulfocálcica mantém a população de ácaros (Brevipalpus phoenicis) abaixo do nível de controle, porém não evita o surgimento de lesões de leprose em ramos, folhas e frutos

O sistema de consórcio de culturas com as frutíferas está proporcionando uma posterior agregação de renda e inclusão de alimentos saudáveis na mesa das famílias das comunidades envolvidas, além de despertar interesse dos vizinhos adjacentes.

O milho e o feijão que foi semeado nas entre linhas na UD da comunidade Quilombola tiveram pouca geminação, provavelmente por ter ocorrido um longo período de seca após o semeio acrescido pela presença de aves no local. Com isso, a área foi novamente preparada e posteriormente, plantada mudas de tomate variedade de mesa e cerejinha. A mandioca e as abóboras que foram implantadas na ocasião da implantação do pomar, pelo sistema de consórcio, já estão sendo consumidas e comercializadas pela comunidade. Já no Assentamento Amparo, a ervilha que foi semeada nas entrelinhas, numa área de $15 \mathrm{~m}^{2}$, foi colhida em torno de $30 \mathrm{~kg}$ de frutos secos, além do consumo da leguminosa ainda verde na vagem. Semeado em época diferente, foi colhido em torno de $80 \mathrm{~kg}$ de amendoim. 
O excedente da produção de quiabo em torno de $20 \mathrm{~kg}$ por semana foi fornecido para o restaurante da UFGD e mercado da cidade. A berinjela, o jiló e a couve flor, foram distribuídos entre as famílias envolvidas, como parte da subsistência familiar conforme figura 4.

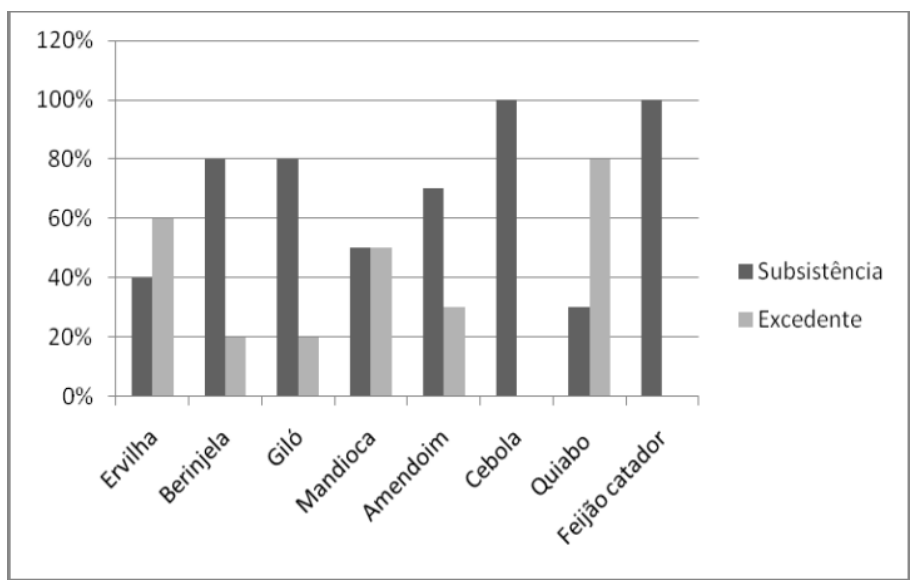

Figura 4 - Produção de culturas nas entrelinhas das plantas frutíferas no sistema de consórcio.

De acordo com Schreiner (1994), o sistema de cultivo em consórcio se constitui uma boa alternativa para as propriedades rurais, pois oferece integração entre preservação ambiental e cultivos agrícolas, para enfrentar os problemas crônicos de baixa produtividade, escassez de alimentos e degradação ambiental generalizada. Esses sistemas podem alcançar bons níveis de sustentabilidade nos seguintes aspectos: "agronômico, pela redução de riscos de pragas e doenças e melhor ciclagem de nutrientes; econômico, pela diversificação das fontes de renda; social, conseqüente da diversificação de mercados e serviços; e ecológico, através da melhoria no balanço hidrológico, conservação do solo e condições para micro e macro faunas e floras".

Esse cultivo simultâneo de duas ou mais culturas, permite assegurar uma subsistência mais estável em termo de renda e alimento, minimizando os riscos decorrentes do monocultivo (COELHO et al. 1994)

$\mathrm{Na}$ escolha das espécies frutíferas para a implantação das UDs, procurou-se utilizar as frutas de maior potencial econômico e as espécies que apresentavam maiores teores de vitaminas, sais minerais e proteínas, além da possibilidade de utilização in natura ou de serem aproveitadas na forma de doces, licor, compotas, geléia e também a produção de frutas ao longo do ano. Também buscou-se a utilização de espécies de frutas bastante apreciadas pela família e ainda a introdução de espécies não tradicionais mas com potencial econômico ou medicinal e que produzam em épocas de entre safra da maioria das espécies.

\subsection{Sistemas Agroflorestais}

No Assentamento Lagoa grande, observou-se várias espécies nativas como o Pequi (Caryocar brasiliense - Caryocaraceae), Mangaba (Hancornia speciosa - 
Apocynaceae), Marolo (Annona coriácea - Annonaceae), Marmelo (Alibertia edulis (L. Rich.) A. Rich - Rubiaceae), ipê amarelo (Tabebuia chrysotricaha - Bignoniaceae), ipê roxo (Tabebuia impetiginosa - Bignoniaceae) angico (Albizia polycephala), aroeira (Anadenathera sp -, jatobá (Hymenaea courbaril L. var. stilbocarpa (Hayne) Lee et Lang - Fabaceae - Caesalpinioideae), barbatimão (Stryphnodendron barbatiman Mart - Fabaceae), guapeva (Pouteria ramiflora radlk), pau terra (Qualea grandiflora), candeia (Gochnatia polimorpha) - Compositae, etc. adjacentes as UDs

Após a implantação das UDs do SAFs, nos lotes determinados houve muitos dias de seca, onde as plantas passaram por uma restrição hídrica mesmo ocorrendo a irrigação manual, acarretando a morte de muitas plantas, em torno de $80 \%$, sendo necessário a reposição quase total do stand. Em uma das unidades, em que havia vegetação de cerrado e que o eucalipto foi plantado sem mexer na flora houve perda total, não sendo possível à reposição.

Os produtos resultantes dos cultivos agrícolas nas entre linhas do eucalipto como mandioca, melancia, abóboras e amendoim, foram utilizadas pelas próprias famílias do assentamento.

Em uma das UDs, houve desenvolvimento espontâneo de Urochloa decumbens, tendo sido orientado o trabalho de capinas em corôa de $1 \mathrm{~m}$ ao redor das plantas de eucalipto para diminuir a competição.

De acordo com Vieira et al. (2007), essa diversificação dos sistemas permite um maior aproveitamento da área cultivada, ao invés de ser feito o replantio das espécies de um determinado sistema, o agricultor prefere cultivar outras espécies, frutíferas, em geral a banana, de forma a ocupar aquele espaço. Com isso, o agricultor pode obter diferentes produtos, além de aumentar a diversidade de espécies e aperfeiçoar o uso da área destinada a este sistema.

Oliveira et al. (2000), verificaram a viabilidade econômica de implantar sistemas agro-silvo-pastoril com eucalipto (consórcio de eucalipto com arroz, soja e pastagens) em áreas de cerrado, visando a produzir madeira para serraria e para energia. Os resultados encontrados permitiram concluir que implantar sistemas agrosilvo-pastoris com eucalipto em região de cerrado é uma opção viável economicamente, desde que, pelo menos, $5 \%$ da madeira produzida seja usada para serraria e a madeira restante seja usada para energia ou para outro fim que alcance valor igual ou mais alto no mercado. Resultado encontrado também por Bolfe e Batistela, (2011), em estudos com sistemas na região de são Tomé-Açú - PA. Os autores indicam um sistema de produção diferenciado com potencial econômico e ambiental, se adotado manejo adequado e racional, considerando-se a estrutura e as potencialidades de produção diversificada.

De acordo com Abdo et al. (2008), os Sistemas Agroflorestais podem ser uma ótima opção para o pequeno agricultor e para o equilíbrio ecológico das propriedades o que o torna uma opção que poderá ser amplamente adotada em propriedades que tenham sua forma de produção classificada como agricultura familiar. Como benefício na adoção de SAFs pode-se citar a variabilidade de espécies utilizadas nos modelos de plantio, a melhoria da capacidade produtiva da terra, otimização da utilização dos recursos naturais disponíveis, se adaptado às condições ecológicas e dos produtores, obtendo assim uma maior produção por unidade de área.

Por fim, cabe salientar que o presente trabalho permitiu evidenciar a importante diversidade de situações vividas pelos agricultores familiares, além de promoverem a valorização de trabalho em grupo, da auto-estima e da criação de uma nova fonte de renda.

Uma pesquisa realizada por Filgueira et al. (2011) revela que a sustentabilidade inserida em comunidades rurais do Paraná como um modelo nos 
agropolos é um importante fator para atingir a forma de desenvolvimento, que tem como um dos objetivos manter os recursos naturais para as gerações futuras e agregar economicamente o processo produtivo.

Outra forma de expressar os trabalhos vivenciado pelo meio acadêmico foi pesquisado por Moraes et al. (2011) que detectaram como estratégia alternativa de difundir o conhecimento oriundo de estudos ser por meio de publicação de artigos científicos, representado em $78,6 \%$

\section{CONSIDERAÇÕES FINAIS}

Considera-se que a perspectiva agroecológica e a implantação de SAFs é uma aliada da agricultura familiar, propiciando a preservação do meio ambiente e a qualidade de vida das famílias, por viabilizar a produção de produtos com qualidade nutricional, preços justos e com potencial para ampliar a renda familiar. Entretanto, a adoção destas práticas pressupõe um processo educativo e de percepção de suas potencialidades, além de exigir a definição de estratégias de resistências frente ao uso de agrotóxicos nos cultivos e a inclusão da diversificação de culturas na propriedade rural. Portanto, a participação dos grupos indica, reiteradamente, que a metodologia qualitativa é um aspecto positivo determinante no processo produtivo, propiciando um despertar para diversificação de cultivos, necessárias para a sustentabilidade econômica e social ambiental.

Neste contexto, a equipe executora procurou valorizar essas potencialidades da produção agroecológica, sem desrespeitar os saberes tradicionais, o modo de vida e as expectivas dos grupos envolvidos, ou seja, buscou-se fomentar o diálogo constante para a definição das atividades e as alternativas produtivas.

\section{REFERÊNCIAS BIBLIOGRÁFICAS}

ABDO, M.T.V.N.; VALERI, S.V.; MARTINS, A.L.M. Sistemas agroflorestais e Agricultura familiar: uma parceria Interessante Revista Tecnologia \& inovação agropecuária, v.1, n.2, p.50-59, 2008.

ALBERTASSE, P.D.; THOMAZ, L.D.; ANDRADE, M.A. Plantas medicinais e seus usos na comunidade da Barra do Jucu, Vila Velha, ES. Revista Brasileira de Plantas Medicinais. v.12, n.3, p. 250-260, 2010.

ANDRADE D. Jr.; OLIVEIRA. C.A.L.; PATTARO, F.C.; SIQUEIRA, D.S. Acaricidas utilizados na citricultura convencional e orgânica: manejo da leprose e populações de ácaros fitoseídeos. Revista Brasileira de Fruticultura, v.32, n.4, p.1028-1037, 2010.

AULER, P.A.M.; PAVAN, M.A.; NEVES, C.S.V.J.; CA RLOS, E.F. Ocorrência de declínio dos citros na região Noroeste do Paraná. Revista Brasileira de Fruticultura, v.33, n.1, p.286-290, 2011.

BOLFE, E.L.; BATISTELLA, M.A. Florística e estrutural de sistemas silviagrícolas em Tomé-Açu, Pará. Pesquisa Agropecuária Brasileira, v.46, n.10, p.1139-1147, 2011.

BUAINAIN, A.M.; ROMEIRO, A.R.; GUANZIROLI, C. Agricultura familiar e o novo mundo rural. Sociologias, v.5, n.10, p.312-347, 2003. 
BURG, I.C.; MAYER, P.H. Alternativas ecológicas para prevenção e controle de pragas e doenças (caldas, biofertilizantes, fitoterapia animal, formicidas, defensivos naturais e sal mineral. Francisco Beltrão: Grafit Gráfica e Editora Ltda, 2001.

CAPORAL, F.R.; COSTABEBER, J.A. Agroecologia e Extensão Rural: Contribuições para a Promoção do Desenvolvimento Rural Sustentável. Brasília: MDA/SAF/DATER, 2007.

COELHO, Y.S.; SENA, M.G.C.; OLIVEIRA, S.L. Sistemas diversificados de produção de citros no trópico semi-árido: uma alternativa para unidades familiares. In: CONGRESSO BRASILEIRO DE FRUTICULTURA, 13., 1994, Salvador, BA. Resumos. p. 349-350,1994.

CORREA Jr, C.; SCHEFFER, M.C.; MING, L.C. Cultivo Agroecológico de plantas medicinais e condimentares. Brasília: Ministério de Desenvolvimento Agrário, 2006.

COSTA, V.P.; MAYWORM, M.A.S. Plantas medicinais utilizadas pela comunidade do bairro dos Tenentes - município de Extrema, MG, Brasil Revista Brasileira Plantas Medicinais, v.13, n.3, p.282-292, 2011.

EMBRAPA. Centro Nacional de Pesquisa de Solos (Rio de Janeiro, RJ). Sistema Brasileiro de Classificação de Solos. -Brasília: Embrapa Produção de Informação; Rio de Janeiro: Embrapa Solos, 1999.

FERREIRA, V.R.; SOUZA, P.M. ; PONCIANO, N.J.; CARVALHO, A.J.C. A fruticultura como alternativa para a produção familiar no âmbito do PRONAF nos municípios de Campos dos Goytacazes e São Francisco do Itabapoana-RJ. Revista Brasileira de Fruticultura. v. 25, n.3, p. 436-439, 2003.

FERREIRA, R.L.F.; GALVÃO, R.O.; MIRANDA JUNIOR, E.B.; ARAUJO NETO, S.E.; NEGREIROS, J.R.S.; PARMEJIANI, R.S. Produção orgânica de rabanete em plantio direto sobre cobertura morta e viva. Horticultura Brasileira, n.2, v.29, p. 299-303, 2011.

FILGUEIRA, T.A.; SANTOS, A.M.; VITURIS, M.N. Desenvolvimento rural sustentável e agropolos. Revista Extensão Rural, v.18, n. 21, p.101-120, 2011.

FILGUEIRA, F.A.R. Novo Manual de Olericultura: agrotecnologia moderna na produção e comercialização de hortaliças. 2. ed. Viçosa - UFV, 2003.

FONTANÉTTI, A.; SANTOS, I.C. Manejo da fertilidade do agroecossistema e a sustentabilidade da agricultura familiar. Informe Agropecuário: Tecnologias para a agricultura familiar: produção vegetal, v.3, n. 254, p. 7-13, 2010.

LAGO, A.; LENGLER, L.; CORONEL, D.A.; SILVA, T.N. AGRICULTURA FAMILIAR DE PRODUTOS ORGÂNICOS: UM OLHAR SOB A ÓTICA DO MARKETING Revista Extensão Rural, v.18, n.13, p. 94-116, 2006. 
MORAES, M.D.; LAFORGA, G.; MARIMON JUNIOR, B.; MARIMON, B.S. Estratégias de difusão do conhecimento da pesquisa agropecuária da Universidade do Estado de Mato Grosso. Revista Extensão Rural, v. 18, n. 22, p. 1-38, 2011.

NIEDERLE, P.A. Delimitando as fronteiras entre mercados convencionais e alternativos para a agricultura familiar. Revista Extensão Rural, v.16, n.18, p. 1-33, 2009.

OLIVEIRA, A. D.; SCOLFORO, J.R.S.; SILVEIRA, V.P. A nálise econômica de um sistema agro-silvo- pastoril com eucalipto implantado em região de cerrado Ciência Florestal, v.10, n.1, p. 1-19, 2000.

PADOVAN, M.P. Manual do Agricultor Agroecológico, Dourados-MS: Edição do Autor, 2007.

PRIMAVESI, A. O manejo ecológico do solo: agricultura em regiões tropicais. São Paulo: Nobel, 2002.

SCHREINER, H. G. Pesquisa em agrossilvicultura no Sul do Brasil: resultados, perspectivas e problemas. CONGRESSO BRASILEIRO SOBRE SISTEMAS AGROFLORESTAIS, 1., v. 2. Porto Velho. Anais... Colombo: EMBRAPA-CNPMF. 1994. p.387-398. 496 p. agrofloresta, ecologia, simulação, sustentabilidade, sociologia, delineamento agrofloresta.

SILVA, J.J.; DANIEL, O.; CRENON, T.; NOGUEIRA, I.M.B. Modelos de sistemas agroflorestais para a mesorregião sudoeste de Mato Grosso do Sul. Revista

Extensão Rural, v.17, n. 19, p. 49-74, 2010.

SOUZA, J.L., de, RESENDE, P. Manual de Horticultura Orgânica. 2.ed. atual e ampliada. Viçosa, MG: Aprenda Fácil, 2006. 843p.

VIEIRA, T. A.; ROSA, L.S.; VASCONCELOS, P.C.S.; SANTOS, M.M.S.; MODESTO, R.S. Sistemas agroflorestais em áreas de agricultores familiares em Igarapé-Açu, Pará: caracterização florística, implantação e manejo. Acta Amazônica, v.37, n.4, p.549-558, 2007.

VALARINI, P.J.; OLIVEIRA, F.R.A.; SCHILICKMANN, S.F.; POPPI, R. Qua lidade do solo em sistemas de produção dehortaliças orgânico e convencional. Horticultura brasileira, v.29, n.4, p. 485-491, 2011.

VILELA, D.; ARAÚJO, P.M.M. Contribuições da Câmaras Setoriais e Temáticas à formulação de políticas Públicas e Privadas para o Agronegócio. Brasília: MAPA/SE/CGAC, 2006. 496p.

ZUBA, S.N.; NOGUEIRA W.C.L.; FERNANDES, L.A.; SAMPAIO, R.A.; COSTA, C.A. Yield and nutrition of tomato using different nutrient sources. Horticultura Brasileira v.2, n. 29, p. 50-56, 2011 